\title{
Los delitos de "caza" con veneno a través de un caso jurisprudencial: Sentencia de 24 de septiembre de 2012, del Juzgado de lo Penal no 5 de Zaragoza, y su apelación ante la Audiencia Provincial.
}

Mertxe Landera Luri $^{1}$

\section{SUMARIO}

a) Introducción.

b) Líneas jurisprudenciales principales en torno a la aplicación del delito de "caza" con veneno.

2.1 Caso representativo: Sentencia de 24 de septiembre de 2012 del Juzgado de lo penal $n$ o 5 de Zaragoza².

\subsubsection{Hechos probados.}

2.1.2 Fallo de primera instancia.

2.2 Cuestiones recurrentes en la jurisprudencia penal en torno al artículo 336 del Código Penal ${ }^{3}$ en su modalidad de uso de veneno.

2.2.1 La determinación del objeto de tutela en el delito de caza con veneno del artículo 336 del Código penal.

2.2.2 La difícil subsunción de algunas de las conductas de uso de veneno en medio natural en el ámbito de la acción típica: "emplear para la caza".

2.2.3 El carácter de delito doloso del tipo penal previsto en el artículo 336: el tipo de dolo requerido.

2.2.4 La relación entre el artículo 336 y el resto de tipos penales de protección de la fauna: distinción en función de la categoría del animal afectado.

2.2.5 La Responsabilidad civil: la relevancia de la indemnización económica en el ámbito de este delito.

\footnotetext{
${ }^{1}$ Profesora de Derecho penal en la Universidad del País Vasco desde 1999. Doctora en Derecho penal. Máster en Criminología. Máster Internacional en Sociología jurídica.

2 Sentencia de 24 de septiembre de 2012 del Juzgado de lo penal $\mathrm{n}^{\circ} 5$ de Zaragoza

${ }^{3}$ Código Penal
} 
2.2.6 La trascendencia del impulso procesal de las Asociaciones de defensa de la Naturaleza: Acción pública/Acusación Particular.

2.2.7 El perfil de los autores del delito y la consecuencia jurídico penal accesoria de inhabilitación para el derecho de cazar.

2.2.8 La consecuencia jurídico-penal principal derivada de la condena: la suspensión de la pena de prisión acordada o la imposición de una mera multa.

3 Conclusión.

\section{INTRODUCCIÓN}

En los últimos años, las condenas penales por colocación de cebos envenenados en la Naturaleza han ido en aumento. La importancia de concienciar de la gravedad de estas conductas se encuentra tras la ingente labor de organizaciones medioambientales tan prestigiosas como WWF/Adena y SEO/Birdlife que ejercitan la acción pública en estos procesos penales.

Estas organizaciones se marcan como objetivo conseguir sentencias ejemplarizantes que generen un cambio de mentalidad en cuanto al uso de veneno como método de control de depredadores y que, por tanto, tengan un efecto pedagógico y disuasorio ${ }^{4}$. De estas declaraciones se desprende su confianza en el sistema penal como medio de erradicar estos comportamientos. Como en muchas otras ocasiones, la elección del recurso al Derecho penal puede cuestionarse, incluso desde la eficacia ${ }^{5}$. Pero no es ése el objetivo de este comentario. Sin duda, en estos casos se está apelando a la faceta del Derecho penal como "configurador de conciencias", lo que ciertamente se hace en otros muchos ámbitos sin que en ellos despierte ningún recelo. Lo cierto es que, desde la perspectiva del Derecho penal como ultima ratio, la persistencia de estas conductas en el tiempo hasta el día de hoy, a pesar de su regulación y sanción en el ámbito administrativo ${ }^{6}$, parece justificar el

4" Ver www.venenono.org

${ }^{5}$ Como se verá más adelante la mayoría de las condenas penales por estos hechos desembocan en el pago de una multa, y en caso de suponer pena de prisión ésta es suspendida.

${ }^{6}$ La Ley 42/2007 de 13 de diciembre de patrimonio natural y biodiversidad en su Anexo VII prevé como procedimientos para la captura o muerte de animales y modos de transporte que quedan prohibidos:

a) medios masivos o no selectivos

- animales ciegos o mutilados utilizados como reclamos.

- grabadores y magnetófonos, aparatos electrocutantes, dispositivos eléctricos y electrónicos que pueden matar o aturdir. 
recurso al Derecho penal, con una protección reforzada, pero, tampoco hay que olvidar, con una intervención mucho más gravosa en los derechos del individuo que la que supone la aplicación de otras áreas del Derecho como por ejemplo, el Derecho administrativo.

Desde un punto de vista técnico jurídico-penal, como el que este análisis acomete, el uso de veneno en el medio natural está sancionado a través de la prohibición establecida en el artículo 336 del Código penal ${ }^{7}$. De todos los delitos relacionados con la actividad cinegética, sin duda, el más grave está constituido por el comportamiento previsto en el artículo 336 del Código penal que sanciona, entre otras conductas, el uso de veneno en el ámbito de la caza. Aunque a priori, y como se acaba de decir, el artículo 336 cabe relacionarse con modos especialmente dañinos de ejercitar la caza, el radio de acción de este tipo penal no se limita a la acción estrictamente de caza ni, por otro lado, a los animales catalogados como cinegéticos, objeto legal de caza. Por el contrario, la fenomenología de este delito nos sitúa ante conductas con un perfil muy concreto: la colocación de cebos envenenados como forma de eliminar los depredadores (rapaces, zorros) que diezman las piezas de caza. Es por ello que también cabe aplicar la sanción prevista en el artículo 336, la más grave del Capítulo IV del título XVI del Código penal, cuando los animales afectados por el veneno se encuentran fuera del ámbito cinegético, y por tanto ajenos en principio a la actividad cinegética estrictamente hablando. Desde un punto de vista técnico, este hecho tiene como consecuencia que la calificación jurídico penal a la que dan lugar

- fuentes luminosas artificiales, espejos, dispositivos para iluminar los blancos, dispositivos de visor que incluyan un convertidor de imagen o un amplificador de imagen electrónico para tiro nocturno.

- armas semiautomáticas o automáticas cuyo cargador pueda contener más de dos cartuchos.

- trampas no selectivas en su principio o en sus condiciones de empleo.

- redes, lazos (sólo para aves), cepos, trampas-cepo, venenos, cebos envenenados o tranquilizantes

- ligas.

- explosivos.

- asfixia con gas o humo.

- ballestas.

- anzuelos (salvo para el ejercicio de la pesca).

7 Según el artículo 336 del Código penal: “El que, sin estar legalmente autorizado, emplee para la caza $o$ pesca veneno, medios explosivos $u$ otros instrumentos o artes de similar eficacia destructiva o no selectiva para la fauna, será castigado con la pena de prisión de cuatro meses a dos años o multa de ocho a veinticuatro meses y, en cualquier caso, la de inhabilitación especial para profesión u oficio e inhabilitación especial para el ejercicio del derecho a cazar o pescar por tiempo de uno a tres años. Si el daño causado fuera de notoria importancia, se impondrá la pena de prisión antes mencionada en su mitad superior". 
este tipo de conductas -colocar veneno en medio natural- sea doble. Duplicidad que atiende, por un lado, al animal afectado, real o potencialmente, lo que da lugar a la aplicación del tipo penal previsto en el artículo 334 y, en menor medida, en el artículo 335. Y, por otro lado, al uso del veneno, en sí mismo considerado, que da lugar a la aplicación del tipo que aquí se analiza previsto en el artículo 336 del Código penal.

Desde un punto de vista concreto, el comentario que sigue analiza el caso de dos miembros de una sociedad de cría de palomas que colocan cebos envenenados como forma de evitar la muerte de las palomas a manos de aves rapaces. La Sentencia condenatoria reúne todas las características recurrentes en esta problemática, resultando especialmente representativa de la lectura jurisprudencial de la prohibición contenida en el artículo 336. Por ello, el análisis que sigue trasciende esta sentencia concreta y abarca cuestiones generales que la jurisprudencia penal aborda en relación con la problemática del delito. En este objetivo último de realizar un repaso de las pautas jurisprudenciales principales en la aplicación de este delito, se explica también la especial atención prestada a la sentencia de instancia del Juzgado no 5 de Zaragoza ${ }^{8}$ y cuya sentencia la Audiencia Provincial ratifica en apelación ${ }^{9}$. La razón de esta inmersión en la Sentencia del tribunal de menor rango radica en la mayor profundización de ésta en las cuestiones de carácter penal. En apelación, sin embargo, los motivos que apoyan el recurso son eminentemente procesales ${ }^{10} \mathrm{y}$, como tales, no dan lugar a nuevas argumentaciones sobre las cuestiones que centran nuestro interés.

\footnotetext{
${ }^{8}$ Sentencia de 24 de septiembre de 2012 del Juzgado de lo penal $\mathrm{n}^{\circ} 5$ de Zaragoza

9" $\underline{\text { SAP Zaragoza 853/2013 }}$

${ }^{10}$ Fundamentalmente, se impugna la prueba obtenida por vulneración del derecho a la inviolabilidad del domicilio (artículo 18.2 CE) ya que las muestras de los restos con veneno se toman de un quemador dentro de terreno vallado perteneciente a la sociedad de colombicultura a la que pertenecen los acusados; así como la apreciación de la prueba en el caso de las declaraciones contradictorias, ratificadas en instrucción pero no en juicio oral, sobre la autoría de los hechos desde la perspectiva de la vulneración de los principios de presunción de inocencia y del derecho a la tutela judicial efectiva.
} 


\section{PRINCIPALES LÍNEAS JURISPRUDENCIALES EN TORNO A LA APLICACIÓN DEL DELITO DE "CAZA" CON VENENO}

Como se adelantó en el apartado anterior, y el título de este segundo apartado pone de relieve, nuestro análisis no se circunscribe estrictamente al contenido de la Sentencia del Juzgado de lo penal no 5 de Zaragoza y su posterior apelación; en su lugar, esta Sentencia es utilizada como muestra representativa de las líneas de interpretación más relevantes de la jurisprudencia penal en torno a la aplicación del delito previsto en el artículo 336 del Código penal en su modalidad de uso de veneno.

\subsection{Caso representativo: Sentencia de $\mathbf{2 4}$ de septiembre de $\mathbf{2 0 1 2}$ del Juzgado no 5 de Zaragoza}

\subsubsection{Hechos probados}

Éstos son los datos que el Juzgado no 5 de Zaragoza considera probados dando lugar a la condena de los acusados, condena posteriormente ratificada en segunda instancia:

1) Alejandro y Artemio pertenecen a una sociedad de colombicultura que tiene unas instalaciones en el término municipal de Valmadrid, dedicándose a la cría y entrenamiento de palomas, que pueden llegar a alcanzar en el mercado un alto valor económico.

2) Como quiera que sus animales sufrían bajas como consecuencia de la acción de otros animales depredadores de la zona, en fechas no determinadas pero entre los meses de febrero y marzo de 2011, los acusados Alejandro y Artemio elaboraron una estrategia consistente en la colocación de unos cebos envenenados consistentes en despojos cárnicos mezclados con un producto químico tóxico de color violáceo denominado carbofurano (cuya utilización está prohibida incluso para la agricultura, por su toxicidad, desde el año 2007), con la finalidad de que las palomas quedaran protegidas por el extermino de sus atacantes.

3) El día 8 de marzo de 2011 fueron encontrados dos cadáveres correspondientes a dos ejemplares adultos de águilas-azor perdiceras que estaban asentadas en la zona, en el paraje Rebollar de Valmadrid, a escasos trescientos metros de las instalaciones de la sociedad de los acusados. Resulta acreditado que las dos águilas murieron por la ingestión de los cebos citados, infectados por la sustancia tóxica del carbofurano, que los acusados habían colocado con absoluto desprecio de las especies que pudieran verse afectadas.

4) Ese mismo día, por el Agente de Protección de la Naturaleza no NUM006 fueron encontrados unos restos del mismo producto tóxico y de los cebos preparados en un quemador sito en el interior de las instalaciones de la sociedad a la que pertenecían los acusados. El referido quemador se encontraba en la zona exterior de dichas instalaciones. 
5) En las mismas fechas, pero días después, en el paraje "La Val", también apareció un ejemplar de zorro común muerto por intoxicación con la misma sustancia, tras haber ingerido un cebo preparado con la referida sustancia.

6) El águila-azor perdicera es un ave incluida como vulnerable en el Anexo del Listado de especies silvestres en régimen de protección especial, y en el Catálogo español de Especies Amenazadas, de acuerdo con el Real Decreto 139/2011 ${ }^{11}$. Igualmente se encuentra incluida y catalogada como especie en peligro de extinción según el Anexo I del Decreto 181/2005 ${ }^{12}$ de 6 de Septiembre del Gobierno de Aragón por el que se modifica parcialmente el Decreto $49 / 1995^{13}$ de 28 de Marzo por el que se regula el catálogo de especies amenazadas de Aragón.

7) El lugar en el que sucedieron los hechos se encuentra dentro de la Zona de Especial Protección para las Aves (ZEPA) Río Huerva y Las Planas, región biogeográfica Mediterránea, y es a su vez Lugar de Interés Comunitario (LIC).

\subsubsection{Fallo en primera instancia}

En base a los hechos anteriormente descritos la Juzgadora de instancia condena a Alejandro y a Artemio como autores penalmente responsables, cada uno de ellos, por un delito contra la fauna del art. 334 del CP, en concurso con un delito del art. 336 del $\mathrm{CP}$, sin concurrencia de circunstancias modificativas de la responsabilidad criminal. Delitos por los que se les imponen las penas de multa de veinticuatro meses con cuota diaria de ocho euros, con una responsabilidad personal subsidiaria de un día de privación de libertad por cada dos cuotas de multa no satisfechas; e inhabilitación para el derecho a la caza por tiempo de cuatro años. Asimismo, en concepto de responsabilidad civil, se dispone como indemnización en favor de la Administración de la Comunidad Autónoma de Aragón la cantidad de 33.015,90 euros, más los intereses legales.

La Audiencia Provincial de Zaragoza a través de Sentencia con fecha de 22 de marzo de $2013^{14}$ confirma esta condena.

\footnotetext{
11" $\underline{\text { http://www.derechoanimal.info/bbdd/Documentos/1231.pdf }}$

12" $\underline{\text { http://www.derechoanimal.info/bbdd/Documentos/1232.pdf }}$

13" $\underline{\text { http://www.derechoanimal.info/bbdd/Documentos/1233.pdf }}$

14" Sentencia de la Audiencia Provincial de Zaragoza 93/2013, de fecha 22 de mayo de 2013
} 


\subsection{Cuestiones recurrentes en la jurisprudencia penal del artículo 336 del Código penal en su modalidad de uso de veneno}

Como ya se ha explicado, a continuación se tratan de forma individualizada las cuestiones recurrentes que forman parte del enjuiciamiento de las conductas de uso de veneno subsumibles en el artículo 336 del Código penal.

\subsubsection{La determinación del objeto de tutela en el delito de caza con veneno del artículo 336 del Código penal}

En un examen penal como el presente, el punto de partida indiscutible debe ser el objeto de protección de la norma aplicada. En ese sentido, la Sentencia de instancia inicia su argumentación sobre la calificación jurídica de los hechos como supuestos del artículo 336 en tanto en cuanto la acción enjuiciada pone en peligro el bien jurídico protegido. En ese sentido, y con cierta confusión, entre el carácter de mera actividad de la acción prevista y el carácter de peligro de la estructura típica respecto a la intensidad del ataque prevista para el bien jurídico ${ }^{15}$, la Sentencia de instancia es, sin embargo, rotunda al afirmar que el comportamiento de Artemio y Alejandro debe encuadrarse en el marco de aquéllas con potencialidad lesiva de afectar al bien jurídico protegido (medioambiente, equilibrio natural en su elemento fauna o biodiversidad) ${ }^{16}$.

En este contexto, hay que hacer notar que la razón de la configuración de este delito como delito de peligro no sólo radica en la importancia del bien jurídico tutelado sino que derivaría, a su vez, de una razón de carácter pragmático que claramente advierte, por ejemplo, el Juzgado de lo penal no 2 de Lleida en su Sentencia de 18 de mayo de $2009^{17}$, porque lo más habitual es que no siempre pueda probarse la magnitud concreta de los efectos del veneno:

\footnotetext{
${ }^{15}$ Existe unanimidad al considerar el delito contenido en el artículo 336 como delito de peligro, lo que legitima la intervención penal a pesar de no haber resultado material lesivo concreto alguno. Así por ejemplo, la Sentencia de 3 de mayo de 2010 del Juzgado de lo penal $n^{\circ} 5$ de A Coruña subsume en el artículo 336 la conducta de impregnar el cadáver de un potro con fenobarbital y abandonarlo en una zona con presencia importante de lobos ibéricos porque "[...] con dicha actuación crearon un grave riesgo para la vida no sólo de los lobos sino de otros animales que pudieran acercarse al cadáver del potro" (Fundamento jurídico cuarto).

${ }^{16}$ Ciertamente, no existe unanimidad en la doctrina penal a la hora de determinar cuál sea el objeto tutelado en los delitos contra la fauna (artículos 334-335-336 CP) aunque mayoritariamente se suela concretar en la idea de biodiversidad. Según el TC en su Sentencia 101/2012 de 8 de mayo de 2012 que declara inconstitucional el artículo 335 del Código penal en la redacción de la Ley orgánica 10/1995 de 23 de Noviembre, a través de la que se aprueba el Código penal se trataría de "la biodiversidad, los recursos naturales y el medio ambiente y, de modo particular, la fauna silvestre" (Fundamento jurídico cinco)

17" http://www.derechoanimal.info/bbdd/Documentos/1234.pdf
} 
"[...] se desconoce el número total de animales afectados, pues los animales al ingerir los embutidos intoxicados no morían de forma instantánea, pudiendo los mismos trasladarse a otras zonas próximas o ir a morir a sus nidos o refugios".

En este contexto, la Sentencia del Juzgado no 5 de Zaragoza, que nos sirve de pauta, incide en el fundamento jurídico penal del reproche del uso de veneno en medio natural concretando que la potencialidad lesiva, exigible a todos los medios sancionables a través del artículo 336, se debe, en el caso del veneno, al carácter no selectivo e indiscriminado del veneno ${ }^{18}$, por un lado, y acumulativo, por otro, de modo que su inserción en la cadena trófica y su perdurabilidad lo convierten en un medio incontrolado con potenciales efectos devastadores, capaces de diezmar especies enteras (Fundamento jurídico segundo).

En este sentido, hay que recordar que el criterio de selectividad es básico en la interpretación de una conducta como encuadrable en el ámbito penal del artículo $336^{19}$. En este contexto, la lesividad propia del medio veneno es aún mayor, pues además de medio no selectivo es un medio masivo, o como expone la juzgadora de instancia, acumulativo, en tanto tiene capacidad para extenderse más allá del individuo que lo ingiere. Sin embargo, cabe echar en falta otro criterio que hace del veneno un medio especialmente reprochable hasta el punto de poder resultar cofundamentador del injusto penal en este caso: la característica de especialmente cruento de la mayoría de los venenos, que provocan un padecimiento, en algunos casos agónico, previo a la muerte, provocando un sufrimiento del animal gratuito y adicional al fallecimiento.

2.2.2. La difícil subsunción de algunas de las conductas de uso de veneno en el medio natural en el ámbito de la acción típica: "emplear para la caza"

Motivo de recurso habitual en las apelaciones a sentencias que condenan por el artículo 336 es la indebida aplicación del precepto por falta de encaje de la actuación enjuiciada con la acción típica descrita por la norma, concretamente, "emplear para la caza". Esta misma objeción se presenta por la defensa de los condenados en segunda instancia ante la Audiencia Provincial de Zaragoza. Sin embargo, esta Audiencia, compartiendo una interpretación jurisprudencial unánime, entiende que también la

\footnotetext{
18 En algunas sentencias se ha puesto en cuestión qué pueda consistir el veneno, por ejemplo, en la Sentencia de 3 de mayo de 2010 del Juzgado de lo penal $n^{\circ} 5$ de A Coruña (Fundamento jurídico quinto) en un caso en que los dueños de caballos en semilibertad afectados por la pérdida de numerosos caballos a manos de los lobos rocían con fenobarbital el cadáver de un potro en una zona habitada por lobos ibéricos. La defensa de los acusados alega que la sustancia fenobarbital no es un veneno sino un medicamento. La argumentación de la juzgadora, sin embargo, apelando al bien jurídico protegido: "[...] usado en altas dosis puede generar efectos adversos en los seres vivos, pudiendo desembocar en su muerte; circunstancia esta que permitiría equiparar sus efectos al veneno [...] no sólo es veneno la sustancia que causa la muerte sino también tiene tal consideración aquélla que es capaz de provocar graves alteraciones funcionales en un ser vivo tal y como sucede en el presente supuesto".

19 Ver sobre el parany como medio de caza selectivo, STS de 22 de junio de 2005, Sala de lo contencioso-administrativo, Sección $5^{\mathrm{a}}$.
} 
acción de causar la muerte a animales silvestres a través de la colocación de cebos envenenados cabe ser integrada en la dicción legal del precepto. Como argumento alude a la definición que de "acción de cazar" proporciona la Ley de caza de Aragón de $5 / 2002$ de cuatro de abril ${ }^{20}$, cuyo segundo artículo establece que "se considera acción de cazar la realizada por el hombre directamente o mediante el uso de armas, animales domésticos y artes o medios apropiados para buscar, atraer, perseguir $o$ acosar animales silvestres con el fin de darles muerte, apropiarse de ellos o facilitar su captura a terceros así como la ejecución de los actos preparatorios que contribuyan a tal fin" (Fundamento jurídico cuarto).

Sobre esta misma controversia, la Magistrada de lo penal en primera instancia acude a una interpretación estrictamente penal considerando que la redacción legal "emplear para la caza" conecta la acción con la exigencia de la presencia de un elemento teleológico o final "para la caza" que se concretaría en la orientación del método utilizado, en este caso veneno, hacia la caza. El modo en que en el presente caso se argumenta, se adhiere a una interpretación ya consolidada que entiende que "también hechos como el presente, tendentes a eliminar depredadores salvajes o asilvestrados para garantizar las capturas futuras se orientan a la caza en el sentido requerido por el tipo".

2.2.3. El carácter de delito doloso del tipo penal previsto en el artículo 336: el tipo de dolo requerido

Otro de los puntos que constituyen motivo de atención de la Magistrada juzgadora de instancia, y relacionado con el anterior, se refiere a la falta de dolo o intención de cazar atribuibles a la acción de colocación de los cebos envenenados. Según la defensa, los acusados habrían colocado los cebos con intención de ahuyentar a los depredadores que estaban matando a las palomas de su propiedad. La Magistrada considera, sin embargo, que de la acción de los acusados puede inferirse un dolo de matar y ello por dos razones. Primera, la declaración del veterinario que realizó la necropsia a los animales envenenados y que explicó que la simple colocación del carbofurano (veneno utilizado) en la tierra o en los arboles habría sido tóxica pero no hubiese sido ingerida por los animales con lo que, en todo caso, podría haberlos ahuyentado, "pero que su colocación en despojos cárnicos revela la intención de que los animales depredadores ingirieran tales cebos y no simplemente se alejaran [...]" (Fundamento jurídico segundo)

Segunda, la interpretación jurisprudencial unánime que deduce el dolo de matar con veneno de la propia colocación del veneno dentro de restos comestibles y en lugares de tránsito de la fauna como puede ser el campo descubierto para el caso de las rapaces.

En relación con lo anterior, y aunque la Magistrada no lo explicite sino indirectamente, el objetivo último de la colocación del cebo, esto es, remediar

\footnotetext{
${ }^{20}$ Ley 5/2002 de cuatro de abril, de caza de Aragón.
} 
posteriores bajas entre la colonia de palomas, es tenida en cuenta para descartar la presencia de un dolo directo en la acción de los condenados. En su lugar, la Magistrada considera que el dolo presente en la acción es un dolo eventual, por tanto, el más débil respecto al elemento volitivo, y así lo expresa a la hora de determinar la pena concreta a imponer. En un párrafo muy significativo la Magistrada se pronuncia en el siguiente sentido: "No se impone una pena de prisión, pese a la gravedad del resultado producido ya que no concurre reincidencia en la conducta y no existe dolo directo sino eventual, debiendo reservarse la pena privativa de libertad para los casos más graves o que merezcan mayor reproche penal" (Fundamento jurídico cinco).

En mi opinión, y sin pretender zanjar la cuestión, cabe cuestionarse si no sería más ajustada al supuesto de hecho la apreciación de un dolo directo pero de segundo grado, definido como aquel en que "el autor no quiere directamente una de las consecuencias que se va a producir, pero la admite como necesariamente unida al resultado principal que pretende ${ }^{\prime 21}$, en este caso, evitar más bajas en su colonia de palomas por medio de la colocación de cebos envenenados con una sustancia, por su cantidad y características, obligadamente, de efectos letales.

2.2.4. La relación entre el artículo $336 \mathrm{CP}$ y el resto de tipos penales de protección de la fauna: distinción en función de la categoría del animal afectado

Como se ha puesto de relieve previamente, el artículo 336 no limita su radio de acción a la muerte por envenenamiento de animales amenazados (artículo 334) sino que también es de aplicación a cualquier animal silvestre que fenece en estas circunstancias, como puede ser el caso de un animal de compañía, un perro que accidentalmente ingiere un cebo envenenado. Es por ello que, el uso de veneno suele suponer un ataque doble: por un lado, la aplicación del artículo 336 se razona en la utilización del veneno y su potencialidad dañina; por otro, la aplicación del artículo 334 o delito de daños, a decir de la jurisprudencia manejada ${ }^{22}$, a raíz de la fauna amenazada o animal doméstico que resulta efectivamente afectada. La técnica jurídico penal con que este ataque doble se canaliza es el concurso ideal, como bien refleja la Sentencia que se comenta. En ésta, los animales afectados, de forma constatada al menos, gozan de distinto grado de protección penal. En un caso, el carácter de animales en peligro de extinción de las águilas azor perdiceras en Aragón condiciona la aplicación del artículo 334. El zorro, sin embargo, no goza de esta protección penal, sino que a decir de parte de la doctrina, incluso, no gozaría de protección penal alguna y sí administrativa. Es por tanto que su muerte no conlleva calificación jurídica doble o adicional a la aplicación del artículo 336 por uso de veneno.

\footnotetext{
${ }^{21}$ MUÑOZ CONDE/GARCIA ARÁN, Derecho Penal. Parte General, $7^{\mathrm{a}}$ edición, tirant lo Blanch, Valencia, 2007, p. 270.

${ }^{22}$ Cabe cuestionarse si no resultaría más adecuado sancionar a través del artículo 337 del Código penal que prevé el delito de maltrato a los animales domésticos, la dicción de este tipo penal permite encuadrar en su ámbito el maltrato "por cualquier medio o procedimiento".
} 
¿La muerte del zorro común no tiene, por tanto, relevancia penal? La relevancia práctica de esta cuestión es evidente si tenemos en cuenta que los animales directamente afectados por las acciones de envenenamiento son depredadores de los animales cinegéticos más valorados como venados y aves y por ello, habitualmente entre los animales objeto directo del envenenamiento se distinguen muy especialmente las rapaces y los zorros. La cuestión a resolver es complicada y requiere de posicionamientos previos que no están conectados directamente con la problemática relativa al delito del artículo 336, fundamentalmente, de la determinación de los animales protegibles a través del artículo 335. Con la concreción que la respuesta requiere en este pequeño marco, habría que decir que la jurisprudencia penal excluye los animales cinegéticos como el zorro del ámbito de protección penal, trasladando las consecuencias de estos actos a la vía administrativa y a la Responsabilidad civil. En este último sentido, la propia sentencia de instancia que analizamos declara en el Fundamento de derecho dedicado a la Responsabilidad civil que: "En cuanto al zorro que también resultó envenenado, no habiendo reclamado la Comunidad Autónoma cantidad alguna por el mismo, siendo la Administración la perjudicada directa por el delito, no procede fijar cantidad alguna" (Fundamento jurídico sexto).

Éste no deja de ser un ejemplo del distinto tratamiento legal (distinto grado de protección) de los animales en función de su categorización, categorización que deriva de la aplicación de una perspectiva instrumental por parte del ser humano.

\subsubsection{La Responsabilidad civil: la relevancia de la indemnización económica en el} ámbito de este delito

Relacionada con la cuestión anterior, y como otra de las características comunes a la jurisprudencia que aplica el delito previsto en el artículo 336 en su modalidad de veneno, hay que significar la relevancia de la Responsabilidad civil como institución que canaliza parte del reproche penal en una concepción economicista de la protección penal de los animales y que sustituye, en mi opinión, en ciertos casos, a una calificación jurídica más apurada al significado penal de las conductas objeto de enjuiciamiento. Así, es habitual encontrar la declaración de la obligación de indemnizar como parte del fallo condenatorio. De esta afirmación genérica se pueden distinguir los siguientes grupos de casos:

a) Casos en que el animal fallecido es un animal doméstico propiedad de un ser humano.- La calificación jurídica, como ya vimos, es doble: por un lado, por la comisión del delito previsto en el artículo 336 por la colocación de cebos envenenados en la naturaleza; por otro, un delito de daños por la afección en la propiedad derivada de la muerte de los animales domésticos. En cuanto a la Responsabilidad civil, ésta suele sustanciarse en un pago compensatorio a favor del propietario del animal, como ejemplo, la Sentencia de 18 de mayo de 2009 del Juzgado no 2 de Lleida: "Por vía de responsabilidad civil los dos penados deberán indemnizar, en forma conjunta y solidaria, a D.V.S. en la cantidad de 
2000 euros, a M.V.C. en la cantidad de 1000 euros y a F.O.A. en la cantidad de 1000 euros, importes correspondientes al valor de los perros de su propiedad que murieron por la ingesta de los cebos envenenados que colocaron los acusados".

b) Casos en que el animal fallecido pertenece a la Administración y goza de nulo interés biodiverso.- Se acude a la calificación por delito previsto en el artículo 336, más la indemnización correspondiente. El caso más habitual, como el que nos ocupa, es el constituido por la muerte de zorros a causa del envenenamiento. Como se acaba de exponer, aquí la muerte del animal daría pie a la calificación jurídica por el delito del artículo 336, más la indemnización pertinente a la Administración, que se cifra en valores tan ridículos como 6 euros (Sentencia del Juzgado no 2 de Ciudad Real de 9 de noviembre de $2007^{23}$ ) y que, en ocasiones, ni siquiera se solicita como en la sentencia que nos sirve de pauta. Si el valor cinegético del animal es considerable ${ }^{24}$ la variación radica, no sólo en una indemnización mucho más generosa, sino, en algunos casos, en el titular de la indemnización, como ocurre en el caso en que la pérdida tiene lugar en un coto privado: el pago se realiza al titular del coto en que se haya producido la pérdida (así, por ejemplo, la Sentencia de 9 de Noviembre de 2007 del Juzgado de lo penal $n$ o 2 de Ciudad Real).

c) Casos en que el animal afectado goza de valor biodiverso porque resulta ser miembro de una especie, genéricamente, amenazada.- Como ya se expuso en el apartado anterior, la calificación jurídico penal pertinente es doble: artículos 334/336 del Código penal y, en lo que ahora interesa, la Responsabilidad civil derivada se concretará en una indemnización a favor de la Administración correspondiente y en una cantidad, a priori, más elevada en función del valor biodiverso o, en concreto, del grado de amenaza.

En cuanto a los criterios que se tienen en cuenta en orden a determinar la cantidad exacta a satisfacer en concepto de Responsabilidad civil, de un examen de la jurisprudencia penal cabe afirmar que resulta determinante la valoración efectuada por los expertos de la Administración correspondiente, por ejemplo el Biólogo y el jefe del equipo de biodiversidad del Departamento de Medio ambiente en la sentencia que comentamos. Desde un punto de vista general, el criterio principal del que deriva la cantidad a satisfacer parece estar constituido por el valor de reposición de los ejemplares (así explícitamente, la Sentencia de 9 de junio de 2011 del Juzgado de lo

\footnotetext{
${ }^{23}$ Sentencia del Juzgado $\mathrm{n}^{\circ} 2$ de Ciudad Real de 9 de noviembre de 2007

24 Ciertamente, la propia fenomenología de estos delitos condiciona el tipo de animales afectados por lo que raramente se da el caso de piezas de caza de valor significativo envenenadas, siendo estas mismas, precisamente, las que se pretenden proteger de los depredadores.
} 
penal $n$ o 6 de Palma de Mallorca ${ }^{25}$ ), valor base a los que en ocasiones se le añaden otros datos como, por ejemplo, el carácter reproductor de los ejemplares afectados, como ocurre en la Sentencia que analizamos. Concretamente, la Comunidad Autónoma de Aragón en sus conclusiones solicita una indemnización por valor de 33.015, 90 euros por las águilas muertas, "por tratarse de dos ejemplares reproductores de una especie en peligro de extinción", cantidad que se acepta en el fallo.

2.2.6 La trascendencia del impulso procesal de las Asociaciones de defensa de la Naturaleza: Acción pública/Acusación Particular

Como se destacó en la Introducción, el aumento de condenas penales por uso de cebos envenados se deriva de la labor de numerosas organizaciones medioambientales que han ejercido la Acción pública en estos procesos. En un repaso a la jurisprudencia penal sobre el delito previsto en el artículo 336 en su modalidad de uso de veneno, es recurrente en la parte acusadora la presencia de organizaciones como SEO/BirdLife y WWF/Adena pero, también otras muchas con un ámbito más restringido, como la Asociación Naturalista de Aragón (ANSAR), en el caso que nos sirve de muestra ${ }^{26}$. Una de las cuestiones que se suscitan en torno a esta personación es, precisamente, cuál sea la carta de naturaleza que legitima su presencia, habiéndose discutido si constituyen, técnicamente, Acusación Particular o no. En este sentido, cabe citar la Sentencia del Juzgado no 5 de A Coruña de 3 de mayo de 2010, donde se discute como cuestión previa la legitimación procesal de la Asociación para la conservación y estudio del lobo ibérico (ASCEL) para actuar como Acusación particular. En la argumentación de la juzgadora que constituye el Fundamento jurídico primero se distingue, citando como base jurisprudencia del TS, entre una "acusación popular en sentido estricto, que es la que sostiene el ofendido por el delito, y una acusación popular ejercitada por quien no es ofendido por el delito, ni es víctima, ni su heredero o representante" (la cursiva es mía). Esta distinción tendría como efectos prácticos inmediatos dos: la exigencia de requisitos cualificados en orden a capacidad, legitimación y postulación, y la no imposición al condenado de las costas ocasionadas por esta acción popular.

Desde una perspectiva general, la cuestión tiene gran relevancia práctica. Es por la exclusión ya de entrada de la multiplicidad de opciones existentes en el caso de

\footnotetext{
${ }^{25}$ Sentencia de 9 de junio de 2011 del Juzgado de lo penal $n^{\circ} 6$ de Palma de Mallorca

${ }^{26}$ Aunque pueda también darse el caso de Federaciones de caza o Asociaciones de cazadores, como ocurre en el caso central de este análisis enjuiciado en la Sentencia del Juzgado de lo penal $\mathrm{n}^{\circ} 5$ de Zaragoza donde la Federación Aragonesa de caza ejerce, a su vez, la Acción pública.
} 
los seres humanos por lo que la legitimación de las Asociaciones de defensa de la Naturaleza y los animales, en sus distintos niveles y versiones, cobra una importancia trascendental para la persecución de estos delitos. De hecho, esta trascendencia y el correcto uso de la institución de la Acción popular pueden invertir el, a priori, consolidado criterio sobre la no imposición de las costas de estas Asociaciones que explicitaba la sentencia anterior. En esta línea, la Sala Segunda del TS en la STS 1318/2005 de 17 de noviembre (RJ 2006\60) ${ }^{27}$ en el conocido caso del Parque natural Sierra de Baza, que exceptúa la doctrina general de no imposición de las costas ocasionadas por la Acción pública (Asociación medioambiental Proyecto Sierra de Baza) a las personas condenadas. Por su interés reproduzco parte de la argumentación del TS al respecto:

"[...] En efecto, el daño que los mismos producen incide sobre bienes colectivos, que son el contenido de los derechos llamados "de tercera generación", de difícil encaje en la categoría del derecho subjetivo convencionalmente entendido (forma jurídica habitual de los bienes penalmente tutelados), que, en general, presupone como titular al individuo singularmente considerado, o en todo caso, individualizado o identificable como tal. En cambio, esta otra aludida categoría de derechos vive en una dimensión que es siempre transpersonal, ya que interesan directamente a sujetos colectivos, integrantes de grupos humanos indeterminados y abiertos. En algunos casos, puede decirse que, en rigor, lo hacen a la ciudadanía en general e incluso a las generaciones futuras, como ocurre con los que inciden sobre el medio ambiente. Siendo así, es patente que tratándose de delitos relativos a este género de derechos el criterio aludido en materia de costas no es el más pertinente. Y lo mismo puede decirse del propio concepto de acusación particular, que presupone la existencia de un inmediatamente ofendido. Mientras, en cambio, la acción popular, es decir, la de los genéricamente afectados, se adecua perfectamente a la naturaleza de estas infracciones. No sólo, la experiencia abona que con frecuencia, en estos años, si alguna protección penal se ha dispensado a tal clase de intereses, más aún, si éstos han llegado a encontrar acogida en la legislación criminal, ha sido, las más de las veces, merced a iniciativas de esa procedencia. Por tanto, y en general, puede muy bien afirmarse que el cauce de la acción popular es el más natural para dar curso a actuaciones de los legítimamente interesados en la persecución de delitos contra los aludidos bienes colectivos, que actúen en la calidad de genéricos perjudicados. Es decir, de la misma forma en que les conciernen las acciones criminales de referencia $Y$ siendo así, en presencia de determinadas condiciones, el mismo criterio de la afectación y el interés, interpretado a tenor de la naturaleza de los bienes y derechos de que se trata, deberá servir para fundar eventuales condenas al pago de las costas de la acusación popular, con perfecto encaje en la previsión del art. 124 CP. Es cierto que el instituto de

${ }_{27 "} \underline{\text { STS } 1318 / 2005 \text { de } 17 \text { de noviembre }}$ 
la acción popular puede ser y ha sido objeto de abuso y de diversos usos instrumentales, en el contexto de estrategias políticas y de otra índole. Pero esto es algo ajeno objetivamente al mismo y que no debe gravar la posición de quienes, haciendo de él un uso acorde con sus fines constitucionales, contribuyan eficazmente a dar efectividad al orden jurídico. Siendo éste un aspecto que debe quedar a la apreciación prudencial expresa que en cada caso deberá hacer el tribunal de quien dependa la decisión. En lo que hace al papel desempeñado por la Asociación Proyecto Sierra de Baza, institución de carácter altruista, nacida para contribuir a la protección del medio natural de ese mismo nombre, es de señalar que ha cumplido a plena satisfacción esas exigencias. Pues, en efecto, ha actuado de forma eficaz y plenamente correcta en el plano procesal, todo en cumplimiento de sus fines sociales específicos, como lo acredita la existencia de no menos de medio centenar de intervenciones documentadas en el trámite, en el que ha tenido un papel fundamental. Es por lo que debe darse lugar al motivo".

Por último, y sin que sea objeto de controversia, la Acusación Particular se ejerce, en todo caso, por las CCAA correspondientes.

2.2.7. El perfil de los autores del delito y la consecuencia jurídico penal accesoria de inhabilitación para el derecho de cazar

Como la Sentencia que da pie a este Comentario pone de relieve, la fenomenología de estas conductas del uso de cebos envenenados nos conecta con un determinado perfil de sujeto activo del delito. En los casos examinados, aunque quepa cuestionar su contexto cinegético, nos encontramos, inequívocamente, en el contexto de una actividad económica cuyo objeto de negocio son los animales atacados por otros a los que se quiere combatir por medio del veneno. Los casos más habituales resultan aquellos en que los sujetos acusados y condenados son arrendatarios de cotos privados de caza (así por ejemplo, la Sentencia 176/09 del Juzgado no 2 de Lleida, la Sentencia de 9 de noviembre de 2009 del Juzgado no 2 de Ciudad Real, Sentencia de 9 de junio de 2011 del Juzgado de lo penal no 6 de Palma de Mallorca), guardas de cotos de caza (Sentencia de 27 de mayo de 2008 del Juzgado de lo penal no 12 de Sevilla ${ }^{28}$, Sentencia de 3 de mayo de 2000 del Juzgado o 2 de Albacete ${ }^{29}$, Sentencia de 8 de febrero de 2001 del Juzgado de lo penal no 1 de Toledo $^{30}$ ) o, como en el caso que se analiza, propietarios de animales objeto de un negocio afectados por los depredadores. En este caso, los acusados Artemio y Alejandro pertenecen a una sociedad de colombicultura que se dedica a la cría y entrenamiento de palomas que pueden alcanzar en el mercado un alto valor económico. En la Sentencia de 3 de mayo

\footnotetext{
${ }^{28}$ Sentencia de 27 de mayo de 2008 del Juzgado de lo penal $n^{\circ} 12$ de Sevilla

${ }^{29}$ Sentencia de 3 de mayo de 2000 del Juzgado $\mathrm{n}^{\circ} 2$ de Albacete

${ }^{30}$ Sentencia de 8 de febrero de 2001 del Juzgado de lo penal $n^{\circ} 1$ de Toledo
} 
de 2010 del Juzgado de lo penal no 5 de A Coruña se trata de propietarios de caballos en semilibertad atacados por el lobo; en la Sentencia de 3 de septiembre de 2010 del Juzgado de lo penal de Tortosa ${ }^{31}$, el negocio consiste en la cría de perdices.

En todo caso, y a nivel penal, la consecuencia es la relevancia que la pena accesoria de inhabilitación adquiere en este ámbito. La inhabilitación prevista en el artículo 336 es doble y acumulativa: la inhabilitación especial para el ejercicio del derecho a cazar y la inhabilitación especial para profesión u oficio. El examen de la jurisprudencia realizado da como resultado una aplicación general de la inhabilitación del derecho a cazar, aplicación mucho más reducida, casi testimonial, en el caso de la profesión u oficio.

2.2.8. La consecuencia jurídico penal principal derivada de la condena: la suspensión de la pena de prisión acordada o la imposición de una mera multa

El artículo 336 prevé como consecuencias jurídico-penales principales, y de forma disyuntiva, la pena de prisión de cuatro meses a dos años $o$ multa de ocho a veinticuatro meses. En este contexto, otro elemento común a la jurisprudencia del delito de caza con veneno analizada se corresponde con la opción mayoritaria por aplicar la pena de multa frente a la pena de prisión. Por citar algunos casos, en este sentido, las citadas Sentencias de 9 de junio de 2011 del Juzgado de lo penal no 6 de Palma de Mallorca; de 3 de mayo de 2010 del Juzgado de lo penal no 5 de A Coruña o la propia sentencia del Juzgado de lo penal no 5 de Zaragoza que da pie a nuestro análisis. Normalmente, las Sentencias no recogen las motivaciones que llevan a esta decisión, excepto, muy significativamente, la Sentencia central que se comenta. En ella, expresamente, se justifica la imposición de la pena de multa: "Se impone a los acusados una pena de multa de 24 meses, con una cuota diaria de 8 euros [...] No se impone una pena de prisión, pese a la gravedad del resultado producido, ya que no concurre reincidencia en la conducta y no existe dolo directo sino eventual, debiendo reservarse la pena privativa de libertad para los casos más graves o que merezcan mayor reproche penal ${ }^{\prime \prime 32}$.

En relación con lo anterior otra nota recurrente consiste, en aquellos casos en que sí se opta por la imposición de una pena privativa de libertad, en el ejercicio por parte del juzgador/a de la posibilidad de suspender la pena de prisión acordada siguiendo lo previsto en los artículos 80 y ss. del Código penal (así la Sentencia de 21 de marzo de 2011 del Juzgado de lo penal no 3 de Tarragona ${ }^{33}$, la Sentencia de 8 de febrero de 2011 del Juzgado de lo penal no 2 de Lleida ${ }^{34}$, entre otras)

\footnotetext{
31" Sentencia de 3 de septiembre de 2010 del Juzgado de lo penal de Tortosa

32 Sin embargo, la pena de inhabilitación para cazar es la más larga constatada en nuestro examen de la jurisprudencia penal del artículo 336: cuatro años.

${ }^{33} \underline{\text { Sentencia de } 21 \text { de marzo de } 2011 \text { del Juzgado de lo penal } n^{\circ} 3 \text { de Tarragona }}$

${ }^{34}$ Sentencia de 8 de febrero de 2011 del Juzgado de lo penal $\mathrm{n}^{\circ} 2$ de Lleida
} 
Ciertamente, estos datos suscitan numerosos comentarios a los que este análisis no puede dar cabida, pero puede preguntarse, brevemente, si el efecto de prevención general al que las Asociaciones conservacionistas fían el recurso al Derecho penal no queda cercenado por la aplicación judicial, en este sentido, de la norma. Por otro lado, si la especial consideración, coherente con una lectura en clave de ultima ratio y en base al principio pro libertatis, no es aquí producto, más bien, de una conciencia judicial de estar protegiendo un bien jurídico penal, fauna, de menor valor frente a la libertad del individuo a afectar con la imposición de la pena de prisión.

\section{a) CONCLUSIÓN}

La especial lesividad del veneno como medio de afección a la fauna parece justificar la intervención del Derecho penal. Además de medio no selectivo como todos los medios sancionados a través del artículo 336 del Código penal, el veneno se distingue como un medio de afección de gran crueldad y extensión con virtualidad de afectar a numerosos animales de forma concatenada. La jurisprudencia penal parece ser consciente de esta especial gravedad apuntalando su carácter de delito de peligro lo que adelanta la intervención penal y hace innecesario, a priori, la prueba de un daño efectivo a causa del uso del veneno.

Sin embargo, estas conductas no tienen por qué quedar constreñidas al ámbito estrictamente cinegético. En este sentido, se fuerza la dicción legal, contra el principio de legalidad, cuando se encuadran en el artículo 336 casos en que no hay conexión, ni siquiera final, de la acción de envenenamiento con la acción de caza. En estos casos, se produce una distorsión de la argumentación penal que podría solventarse con la tipicidad de la conducta de uso de veneno en la Naturaleza con independencia del contexto en el que este ocurra, siempre que queden satisfechas las exigencias de antijuridicidad material que requieren la puesta en peligro o lesión del bien jurídico protegido.

Lo que sí constituye un dato recurrente es el interés económico subyacente a estas conductas de envenenamiento. En este sentido, la jurisprudencia penal que aplica los delitos contra la fauna y, también el delito del uso de veneno en este ámbito, es reflejo de una concepción en clave económica de los animales. Concepción especialmente visible en la relevancia de la indemnización económica en la aplicación del artículo 336 y que, paradójicamente, se encuentra en la base motivadora de estas conductas. 